\title{
In Vivo Mapping of Cholinergic Terminals in Normal Aging, Alzheimer's Disease, and Parkinson's Disease
}

\author{
D. E. Kuhl, MD, ${ }^{*}$ S. Minoshima, MD, PhD, ${ }^{*}$ J. A. Fessler, $\mathrm{PhD},{ }^{*}$ K. A. Frey, MD, PhD,${ }^{*} \dagger$ \\ N. L. Foster, MD, $\dagger$ E. P. Ficaro, PhD, ${ }^{*}$ D. M. Wieland, PhD, ${ }^{*}$ and R. A. Koeppe, PhD*
}

\begin{abstract}
To map presynaptic cholinergic terminal densities in normal aging $(n=36)$, Alzheimer's disease $(\mathrm{AD})(\mathrm{n}=22)$, and Parkinson's disease (PD) ( $\mathrm{n}=15$ ), we performed single-photon emission computed tomography using $\left[{ }^{123} \mathrm{I}\right]$ iodobenzovesamicol (IBVM), an in vivo marker of the vesicular acetylcholine transporter. We used coregistered positron emission tomography with $\left[{ }^{18} \mathrm{~F}\right]$ fluorodeoxyglucose for metabolic assessment and coregistered magnetic resonance imaging for atrophy assessment. In controls (age, 22-91 years), cortical IBVM binding declined only 3.7\% per decade. In AD, cortical binding correlated inversely with dementia severity. In mild dementia, binding differed according to age of onset, but metabolism did not. With an onset age of less than 65 years, binding was reduced severely throughout the entire cerebral cortex and hippocampus (about 30\%), but with an onset age of 65 years or more, binding reductions were restricted to temporal cortex and hippocampus. In PD without dementia, binding was reduced only in parietal and occipital cortex, but demented PD subjects had extensive cortical binding decreases similar to early-onset AD. We conclude that cholinergic neuron integrity can be monitored in living $\mathrm{AD}$ and $\mathrm{PD}$ patients, and that it is not so devastated in vivo as suggested by postmortem choline acetyltransferase activity (50-80\%).
\end{abstract}

Kuhl DE, Minoshima S, Fessler JA, Frey KA, Foster NL, Ficaro EP, Wieland DM, Koeppe RA. In vivo mapping of cholinergic terminals in normal aging, Alzheimer's disease, and Parkinson's disease. Ann Neurol 1996;40:399-410

Until recently [1], noninvasive measure of cholinergic terminal loss has not been possible in living human brain. Instead, activity decline of choline acetyltransferase (ChAT), the enzyme that catalyzes synthesis of acetylcholine (ACh), has been used extensively as a postmortem marker for the decline of cholinergic neurons, notwithstanding that loss of enzyme activity need not equate to loss of neurons $[2,3]$. In demented patients with Alzheimer's disease (AD) [4-6] and Parkinson's disease (PD) $[7,8]$, postmortem studies have demonstrated consistently a selective loss of basal forebrain cholinergic neurons [9-11] and markedly decreased $(50-80 \%)$ ChAT activity in the associated afferent projection areas, ie, cerebral cortex and hippocampus. Although cholinergic deficit is unlikely to be the sole determinant of cognitive decline in $\mathrm{AD}$ or $\mathrm{PD}$, the severity of cortical ChAT decline in these disorders has been found consistently to be correlated with cognitive decline [12-14], while other cortical measures of neuropeptides and amines and their metabolites have not [14]. The evidence is not clear that cholinergic deficit is a significant consequence of normal human aging [15]. To evaluate the distribution of cholinergic neuronal integrity within living human brain in normal aging, $\mathrm{AD}$, and PD, we performed single-photon emission computed tomography (SPECT) using $\left[{ }^{123} \mathrm{I}\right]$ iodobenzovesamicol ([$\left.\left.{ }^{123} \mathrm{I}\right] \mathrm{IBVM}\right)[16]$, an analogue of vesamicol that binds to the presynaptic vesicular acetylcholine transporter (VAChT) [17] and that consequently serves as an in vivo marker of presynaptic cholinergic terminal density [1]. These measures were compared then with corresponding concomitant measures from positron emission tomography (PET) using $\left[{ }^{18} \mathrm{~F}\right]$ fluorodeoxyglucose (FDG) for assessment of cerebral glucose utilization and from magnetic resonance imaging (MRI) for assessment of atrophy. Our scan data indicated that cortical cholinergic terminals undergo only small age-dependent losses in normal aging, are depleted more in mildly demented $A D$ patients when disease onset is earlier than age 65 years rather than later, and are not so devastated in $\mathrm{AD}$ or $\mathrm{PD}$ as implied by postmortem determinations of ChAT activity.
From the *Division of Nuclear Medicine and $†$ Department of Neurology, University of Michigan, Ann Arbor, MI.

Received Jan 30, 1996, and in revised form Feb 28. Accepted for publication Apr 1, 1996.
Address correspondence to Dr Kuhl, University of Michigan Hospitals, Division of Nuclear Medicine, 1500 East Medical Center Drive, UH B1 G412/0028, Ann Arbor, MI 48109-0028. 
Table 1. Characteristics of Subject Groups ${ }^{\mathrm{a}}$

\begin{tabular}{|c|c|c|c|c|c|c|}
\hline Group & No. & Age $(y r)$ & Duration $(y r)$ & CDR & MMSE & $\mathrm{H} \& \mathrm{Y}$ \\
\hline \multicolumn{7}{|l|}{ Alzheimer's disease } \\
\hline Early onset & 13 & $63 \pm 3$ & $6 \pm 4$ & $1.8 \pm 0.8$ & $13 \pm 6$ & \\
\hline Late onset & 9 & $76 \pm 5$ & $6 \pm 2$ & $1.8 \pm 0.8$ & $12 \pm 7$ & \\
\hline \multicolumn{7}{|l|}{ Parkinson's disease } \\
\hline Not demented & 9 & $59 \pm 7$ & $4 \pm 3$ & $0 \pm 00$ & $28 \pm 1$ & $2 \pm 1$ \\
\hline Demented & 6 & $77 \pm 5$ & $8 \pm 6$ & $1.1 \pm 0.7$ & $21 \pm 6$ & $3 \pm 1$ \\
\hline
\end{tabular}

${ }^{2}$ Characteristics of subject groups. Values are mean $\pm \mathrm{SD}$.

$\mathrm{CDR}=$ Clinical Dementia Rating [20]; MMSE = Minimental Scale Exam [67]; H\&Y = Hoehn and Yahr clinical disability rating [68]

\section{Subjects and Methods \\ Subjects}

The total control group for test of age effect was 36 normal subjects (19 women, 17 men), distributed throughout ages ranging from 22 to 91 years. A subgroup of 17 elderly normal controls (age, $71 \pm 10$ years; 7 women, 10 men) was used for comparison with the $\mathrm{AD}$ and PD groups. Normal subjects had no history of significant general medical, neurologic, or psychiatric illness, head injury with loss of consciousness, or drug or alcohol dependence, and were taking no medications with central nervous system actions. AD and PD subjects were taking no medications with actions known to affect cerebral metabolism or the central cholinergic system. All clinical diagnoses were made by neurologists. The total $\mathrm{AD}$ group was 22 subjects, all of whom were required to have a clinical diagnosis of probable $\mathrm{AD}$ [18] and prior FDG-PET evidence of bilateral posterior parietal hypometabolism typical of AD [19]. One subgroup of 13 patients had early-onset disease (at age 64 years or younger); a second subgroup of 9 patients had late-onset disease (at age 65 years or older). There was a family history of $\mathrm{AD}$ in $61 \%$ of the early-onset group and in $56 \%$ of the late-onset group. These $\mathrm{AD}$ volunteers were sought out to equalize the range and average severity of cognitive impairment within the two subgroups (Table 1). The total PD group was 15 subjects who had a clinical diagnosis of PD (see Table 1). One subgroup of 9 patients was not demented. In a second subgroup of 6 patients, PD had been present for at least 6 months prior to the onset of a complaint of memory loss or intellectual decline. Three of these patients had suspected dementia with a Clinical Dementia Rating (CDR) [20] score of 0.5; the other 3 patients had confirmed progressive dementia (CDR $=1,2,2$ ).

\section{Radiotracers}

IBVM was prepared by oxidative radiciodination of the respective (-)-5-tributyltin precursor, with specific activity greater than $1.11 \times 10^{9} \mathrm{MBq} \mathrm{mmol}^{-1}(30,000 \mathrm{Ci} /$ $\mathrm{mmol}$ ) [16], and was injected intravenously as a $370 \mathrm{MBq}$ $(10 \mathrm{mCi})$ dose. To minimize iodine uptake in the thyroid gland, each subject was given oral Lugol's solution (one drop three times daily) for 1 day prior and for 3 days after the study and an oral laxative (Dulcolax R, CIBA, Summit, NJ) 1 day after the $\left[{ }^{123} \mathrm{I}\right] \mathrm{IBVM}$ injection, to reduce radiation exposure to the bowel [1]. FDG was prepared by direct nucleophilic exchange on a quaternary 4-aminopyridium resin [21] and was injected intravenously as a $370 \mathrm{MBq}(10 \mathrm{mCi})$ dose. The effective dose equivalent for [ $\left.{ }^{123} \mathrm{I}\right] \mathrm{IBVM}$ was $14.2 \mathrm{mSv}$ $(1.42 \mathrm{Rem})$ and for FDG was $10.0 \mathrm{mSv}(1.00 \mathrm{Rem})$.

\section{Scan Protocols}

In the $\left[{ }^{123} \mathrm{I}\right]$ IBVM-SPECT protocol for tracer kinetic analysis, brain [ $\left.{ }^{123} \mathrm{I}\right]$ IBVM images were collected sequentially over the first 4.5 hours following injection and for 1 hour on the following day [1]. The cerebral tracer input function was determined from metabolite-corrected radial arterial blood samples. In the simplified scan protocol, three image sets, as follows, were obtained in each subject without measuring arterial tracer input function: (1) 0 to 30 minutes (for transport index and anatomy), (2) 3 hours to 3 hours 30 minutes (for striatum and cortex anatomy), and (3) 22 hours to 23 hours (for binding index). Reconstructed spatial resolution of the SPECT tomograph (Prism 3000, Picker International, Cleveland, $\mathrm{OH}$ ) was $13.5 \mathrm{~mm}$ (full width, half maximum [FWHM]) in the center of the transverse plane and axially. FDG-PET scans were performed 30 minutes following injection. Reconstructed spatial resolution of the PET tomograph (Siemens Model 921, CTI Inc, Knoxville, TN) was $8.4 \mathrm{~mm}$ (FWHM) in the center of the transverse plane and $7.5 \mathrm{~mm}$ (FWHM) axially. The MRI scanner (0.5 Tesla, Picker International, Cleveland, $\mathrm{OH}$ ) was used for proton density images (repetition time [TR] 3,000 $\mathrm{msec}$, echo time [TE] $30 \mathrm{msec}$ ) and T2 images (TR 3,000 $\mathrm{msec}$, TE $100 \mathrm{msec}$ ) with 7.0mm-thick axial slices.

\section{SPECT and PET Image Processing}

Methods for SPECT image processing were described previously [1]. In brief, head motion was corrected using fiducial markers in each set of frames. Frames obtained on the first and second days were coregistered to the same orientation by using a computer algorithm based on image similarity [22]. An FDG-PET image set corresponding to the $\left[{ }^{123} I\right]$ IBVM-SPECT image set was coregistered in the same manner. Image sets were transformed anatomically to the standard stereotactic coordinate system [23, 24], and localized activities were extracted using stereotaxic-based predefined volumes of interest (VOIs) for subsequent analyses.

The locations of the predefined VOIs and their atlasindicated [23] Brodmann cortical areas were as follows: frontal association cortex $6,8,9,10,11,44,45,46$, and 47; parietal association cortex $5,7,39$, and 40 ; temporal association cortex 21,22, 37, and 38; occipital cortex 17, 18, and 
19; primary visual cortex 17; posterior cingulate cortex 23 and 31; anterior cingulate cortex 24 and 32; and "hippocampus" (includes parahippocampal, fusiform gyri, and amygdala complex, as well as the hippocampal formation) 27, 28, 34 , and 35 . VOIs for the thalamus, striatum, and cerebellum also were predefined. Activities were averaged (area weighted) within each VOI. VOI activities were measured separately for both hemispheres, but left- and right-sided values were averaged together prior to the subsequent analysis.

In addition, cerebral activity in three dimensions was projected to the lateral and medial surface of the brain along lines normal to the surface [25], and between-group comparisons using $t$ statistics were performed on a pixel-by-pixel basis. To demonstrate regional patterns of functional alterations, two-sample $t$-statistic values were calculated on a pixel-by-pixel basis between normal controls and a group of patients, and then transformed to $Z$ values by using a probability integral transformation. Prior to the analysis, homologous pixels in both hemispheres were averaged together, resulting in symmetrical appearance in superior and inferior views.

\section{Tracer Kinetic Analysis}

Fitted parameters reflecting transport $\left(K_{1}\right)$ and binding site density index $\left(k_{3}\right)$ were determined using a three-compartment model [1]. All subjects had zonal [123I]IBVM binding indices determined as the ratio of regional activity to cerebellar activity as measured from the brain image made 22 hours after injection. Full tracer kinetic analysis was performed on the 36 normal control subjects, $11 \mathrm{AD}$, and $7 \mathrm{PD}$ subjects to assure that the choice of cerebellum as a normalizing reference region was proper (ie, no change with age or disease) and to demonstrate equivalence of zonal measures based on simple normalizing of the delayed activity image and those based on more rigorous, but more complicated, kinetic analysis. Cerebellar merabolism is nearly normal in AD and PD $[19,26]$, and so, for consistency, corresponding metabolic indices were normalized to the cerebellum also and were determined from FDG scan data in 16 of the 17 elderly normal control subjects and in all $22 \mathrm{AD}$ and $15 \mathrm{PD}$ subjects. For comparisons, all indices were expressed as percentages of the mean normal values from the elderly control group.

\section{Atrophy Assessment}

To determine the contribution of tissue atrophy to cortical binding and metabolic declines, partial volume effects on all VOI data were assessed for both [ $\left.{ }^{123} \mathrm{I}\right] \mathrm{IBVM}$ and FDG studies in 10 of the 17 elderly normal controls, in 15 of the 22 AD patients ( 9 early onset, 6 late onset), and in each of the 15 PD patients. Proton density and T2-weighted MRI scans were registered to the $\left[{ }^{123} \mathrm{I}\right] \mathrm{IBVM}-\mathrm{SPECT}$ studies [27]. MRI image sets were segmented into brain and nonbrain (cerebrospinal fluid) structures. Brain structures were assigned a value of 1 and nonbrain structures a value of 0 . The segmented MRI data sets were transformed to SPECT orientations by using the transformation matrices determined from the original proton density and T2 data sets. These realigned segmented MRI data sets were then smoothed with a threedimensional Gaussian filter set to match approximately the reconstructed resolution of SPECT (15 mm FWHM) and
PET ( $8 \mathrm{~mm}$ FWHM) image sets. All voxel values in the smoothed segmented MRI data then had values ranging from 0.0 to 1.0. VOIs placed on the SPECT and PET data sets were then applied to the smoothed MRI data sets to yield a percent-tissue (or tissue fraction) value for each VOI, which was applied as an atrophy-partial volume correction term for each VOI of each subject. The VOI measures, with and without atrophy correction, were compared.

\section{Statistical Analysis}

Statistical methods included standard correlational analysis for derermining relationships between different imagederived measures (eg, $\left[{ }^{123} \mathrm{I}\right] \mathrm{IBVM}$ binding index versus parametric $k_{3}$ ), between imaging results and subject age, and between imaging results and cognitive measures. A two-factor repeated-measures analysis of variance (ANOVA) with gender and $\left[{ }^{123} I\right] I B V M$ binding index as factors and different regions as the repeated measure was used to examine gender effects in the normal control group. Additional two-factor ANOVAs were performed with subject group (diagnosis) and imaging measure ([$\left.{ }^{123} \mathrm{I}\right]$ IBVM binding index or FDG metabolic index) as factors. An ANOVA was performed to compare age-matched normal controls and the two AD subgroups (early and late onset), while a separate ANOVA was performed to compare controls and the two PD subgroups (PD and PD with dementia). For regions showing a significant effect across subject groups, individual $t$ tests were performed to compare each patient subgroup versus normal controls for both [ $\left.{ }^{123} \mathrm{I}\right]$ IBVM and FDG measures (Tables 2 and 3). The reported results do not include corrections for multiple comparisons; however, with 10 regions examined for two separate patient subgroups and two different imaging measures, a conservative multiple comparison adjustment would require a significance level of $p<0.001$.

\section{Results}

\section{Normalization}

In normal controls, cerebellar $k_{3}$ derived from tracer kinetic analysis did not change with aging $(\mathrm{n}=36, \mathrm{p}$ $=0.28)$ and was normal in AD $(n=11)$ and PD (n $=7$ ). Recognizing this measured stability, and previous reports of nearly normal cerebellar metabolism in $\mathrm{AD}$ and PD $[19,26]$, all regional measures were normalized to those of the cerebellum, a process that reduced the coefficient of variation for $k_{3}$ in normal cerebral cortex from 22 to $16 \%$ and that permitted use of relative 22 hour count distributions as an alternative to the more complicated and time-consuming tracer kinetic analysis. The correlation was very high $(r=0.947)$, and the relationship was very linear between $k_{3}$ values normalized to cerebellum and the 22-hour static data, also normalized to cerebellum (Fig 1). Regression analysis yielded a slope of 1.02 and near-zero intercept of 0.08 . Near $90 \%$ of the variability in the 22 -hour data values was predicted by differences in $k_{3}\left(r^{2}=0.896\right)$. Accordingly, $\left.{ }^{123} I\right]$ IBVM binding indices were based subsequently on the more simple second-day count distributions, rather than on kinetically derived $k_{3}$ values. 


\begin{tabular}{|c|c|c|c|c|}
\hline & \multicolumn{2}{|c|}{$\left[{ }^{123} \mathrm{I}\right][\mathrm{BVM}$ Binding Index } & \multicolumn{2}{|c|}{ Metabolic Index } \\
\hline & $\begin{array}{l}\text { Early Onset } \\
(\mathrm{n}=13)\end{array}$ & $\begin{array}{l}\text { Late Onset } \\
(\mathrm{n}=9)\end{array}$ & $\begin{array}{l}\text { Early Onset } \\
(\mathbf{n}=13)\end{array}$ & $\begin{array}{l}\text { Late Onset } \\
(\mathrm{n}=9)\end{array}$ \\
\hline Cerebral cortex & $70 \pm 9^{b}$ & $86 \pm 18$ & $84 \pm 10^{b}$ & $84 \pm 7^{b}$ \\
\hline Frontal & $68 \pm 11^{b}$ & $90 \pm 21$ & $82 \pm 14^{\mathrm{b}}$ & $85 \pm 9^{c}$ \\
\hline Temporal & $58 \pm 7^{b}$ & $72 \pm 16^{c}$ & $79 \pm 11^{b}$ & $79 \pm 9^{b}$ \\
\hline Parietal & $59 \pm 11^{b}$ & $83 \pm 22$ & $67 \pm 12^{b}$ & $73 \pm 9^{b}$ \\
\hline Occipital & $65 \pm 9^{b}$ & $85 \pm 17$ & $82 \pm 11^{b}$ & $82 \pm 6^{b}$ \\
\hline Primary visual & $73 \pm 12^{b}$ & $93 \pm 23$ & $96 \pm 8$ & $88 \pm 9^{d}$ \\
\hline Postcingulate & $68 \pm 10^{b}$ & $83 \pm 26$ & $74 \pm 13^{b}$ & $72 \pm 14^{b}$ \\
\hline Antecingulate & $84 \pm 16^{\mathrm{d}}$ & $90 \pm 22$ & $95 \pm 13$ & $88 \pm 13^{\mathrm{d}}$ \\
\hline Hippocampus & $70 \pm 23^{\mathrm{d}}$ & $72 \pm 13^{d}$ & $95 \pm 11$ & $88 \pm 15$ \\
\hline Striatum & $92 \pm 20$ & $99 \pm 22$ & $102 \pm 8$ & $93 \pm 10$ \\
\hline Thalamus & $77 \pm 12^{d}$ & $86 \pm 19$ & $96 \pm 10$ & $91 \pm 6$ \\
\hline
\end{tabular}

${ }^{2}$ Indices are percentages (mean \pm SD) of mean normal values $(n=17)$, without atrophy correction.

Significance of difference from normal (single-tailed unpaired $t$ tests): ${ }^{b} p<0.0001 ;{ }^{c} p<0.001 ;{ }^{d} p<0.01$. IBVM = iodobenzovesamicol.

Table 3. Indices Measured in Parkinson's Disedse

\begin{tabular}{|c|c|c|c|c|}
\hline & \multicolumn{2}{|c|}{$\left[{ }^{123} I\right] I B V M$ Binding Index } & \multicolumn{2}{|c|}{ Metabolic Index } \\
\hline & $\begin{array}{l}\text { Nondemented } \\
(\mathrm{n}=9)\end{array}$ & $\begin{array}{l}\text { Demented } \\
(\mathrm{n}=6)\end{array}$ & $\begin{array}{l}\text { Nondemented } \\
(\mathrm{n}=9)\end{array}$ & $\begin{array}{l}\text { Demented } \\
(\mathrm{n}=6)\end{array}$ \\
\hline Cerebral cortex & $91 \pm 18$ & $66 \pm 13^{b}$ & $93 \pm 5^{d}$ & $88 \pm 11^{d}$ \\
\hline Frontal & $95 \pm 21$ & $67 \pm 15^{b}$ & $93 \pm 5$ & $88 \pm 12^{d}$ \\
\hline Temporal & $86 \pm 18$ & $62 \pm 13^{b}$ & $95 \pm 5$ & $94 \pm 10$ \\
\hline Parietal & $81 \pm 18^{d}$ & $60 \pm 14^{b}$ & $92 \pm 10$ & $81 \pm 7^{b}$ \\
\hline Occipital & $79 \pm 15^{d}$ & $61 \pm 12^{b}$ & $91 \pm 7^{\mathrm{d}}$ & $86 \pm 7^{c}$ \\
\hline Primary visual & $81 \pm 19$ & $65 \pm 16^{c}$ & $90 \pm 6^{\mathrm{d}}$ & $86 \pm 6^{c}$ \\
\hline Postcingulate & $92 \pm 19$ & $55 \pm 9^{b}$ & $88 \pm 9^{d}$ & $77 \pm 13^{\circ}$ \\
\hline Antecingulate & $105 \pm 27$ & $78 \pm 15^{d}$ & $98 \pm 6$ & $93 \pm 16$ \\
\hline Hippocampus & $86 \pm 19$ & $68 \pm 31$ & $89 \pm 4^{\mathrm{d}}$ & $101 \pm 18$ \\
\hline Striatum & $108 \pm 28$ & $92 \pm 22$ & $96 \pm 5$ & $99 \pm 8$ \\
\hline Thalamus & $95 \pm 28$ & $84 \pm 23$ & $93 \pm 5$ & $92 \pm 15$ \\
\hline
\end{tabular}

${ }^{\mathrm{a}}$ Indices are percentages (mean $\pm \mathrm{SD}$ ) of mean normal values $(\mathrm{n}=17)$, without atrophy correction.

Significance of difference from normal (single-tailed unpaired $t$ tests): ${ }^{b} p<0.0001 ;{ }^{c} p<0.001 ;{ }^{d} p<0.01$

IBVM = iodobenzovesamicol.

\section{Normal Controls}

In normal controls $(\mathrm{n}=36)$, across seven decades of age, the normalized $\left[{ }^{123} I\right] I B V M$ binding index was negatively correlated with age at $p<0.05$ in all regions, except the hippocampus and occipital cortex. In cerebral cortex (Fig 2), the decline was approximately $3.7 \%$ per decade, with no correction for atrophy. The striatum/cerebral cortex ratio for $\left[{ }^{123} \mathrm{I}\right] \mathrm{IBVM}$ binding index $(\mathrm{n}=36)$ was $5.17 \pm$ 0.82 (mean $\pm S D$ ). Intersubject coefficients of variation $(\mathrm{COVs})$ for $\left[{ }^{123} \mathrm{I}\right] \mathrm{IBVM}$ binding indices ranged from 10 to $30 \%$ across regions and were largest in the hippocampus $(\sim 30 \%)$. Variability was nearly identical in young and elderly normals. In 5 test/retest subjects, intrasubject COV measured 5 to $13 \%$, which compares with an intersubject COV of $\sim 20 \%$. No gender differences were observed in the $\left.{ }^{123} \mathrm{I}\right] \mathrm{IBVM}$ binding indices of normals $(\mathrm{n}=36)$. A two-factor repeated-measures ANOVA testing gender and region showed no gender effect and no gender-by-region interactions.

\section{Alzheimer's Disease}

In $\mathrm{AD}$ patients $(\mathrm{n}=22)$, $\left[{ }^{123} \mathrm{I}\right] \mathrm{IBVM}$ binding of cerebral cortex correlated negatively $(p=0.016)$ with the severity of dementia as measured by the CDR [20] (Fig $3)$. When dementia was mild or moderate, cerebral cortical binding was more markedly reduced in early-onset than in late-onset patients, but binding reductions were similar when dementia was severe (see Fig 3). ANOVA indicated significant differences between groups (control, early-onset $A D$, late-onset $A D$ ) in all regions ex- 


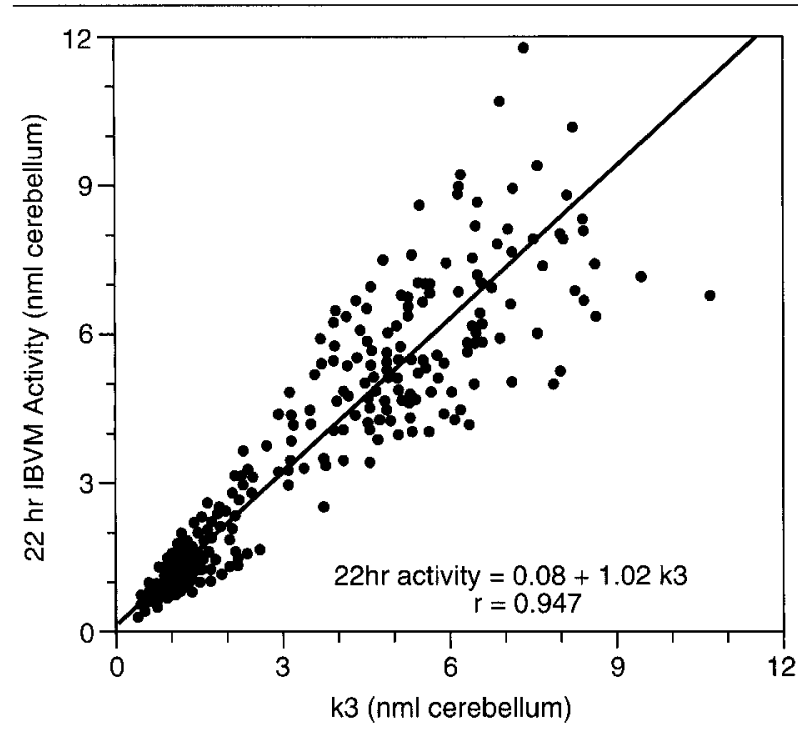

Fig 1. The relative cerebral distribution of [ ${ }^{123}$ I]iodobenzovesamicol ([I23 IJIBVM) activity after 22 hours was equivalent to, and could substitute for, the relative binding index $\mathrm{k}_{3}$ derived from tracer kinetic analysis. Data represent 12 individual brain regions from each of 54 subjects ( 36 normal controls, 11 Alzheimer's disease, and 7 Parkinson's disease) and are normalized to the cerebellum.

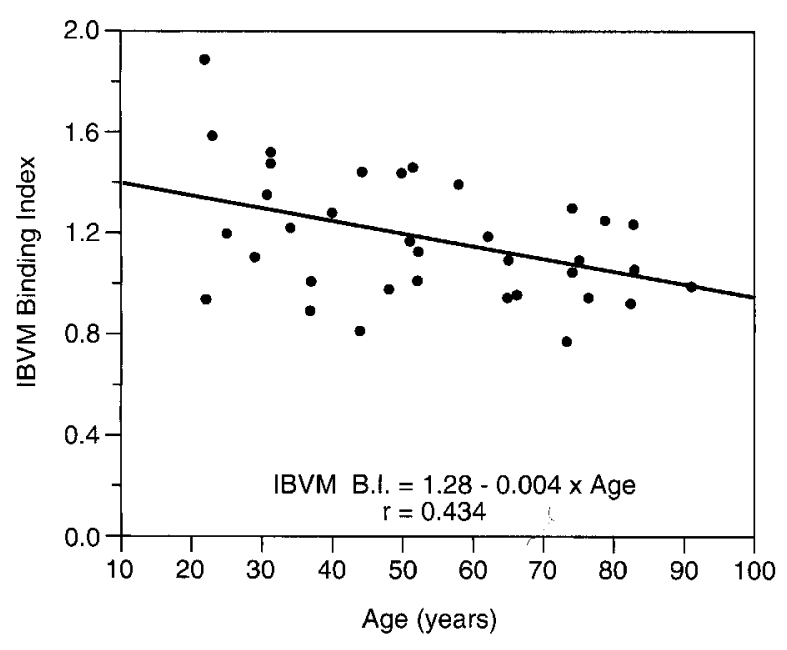

Fig 2. Iodobenzovesamicol (I23 IJIBVM) binding in cerebral cortex declined only approximately $3.7 \%$ per decade in normal aging $(n=36)$. No age effect was found in hippocampal binding. These data are without atrophy correction. B.I. $=$ binding index

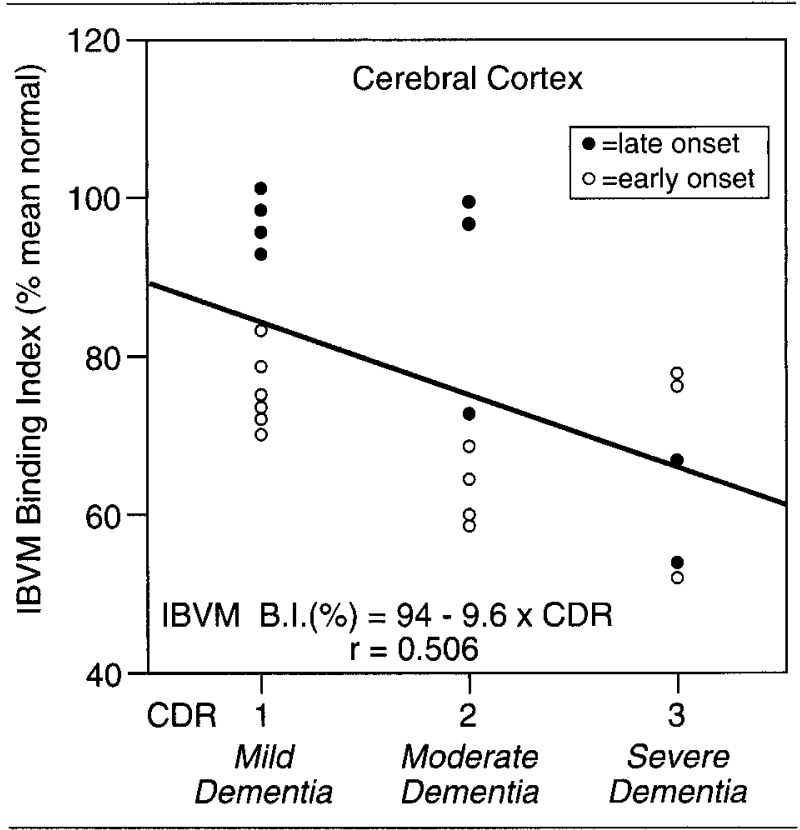

Fig 3. In Alzheimer's disease patients $(n=22)$, [123I]iodobenzovesamicol ([123 IJIBVM) binding (\% of mean normal) in cerebral cortex correlated negatively $(\mathrm{p}=0.016)$ with the severity of dementia. When dementia was mild or moderate, cerebral cortical binding was more markedly reduced in early-onset than in late-onset patients. B.I. = binding index; $C D R=$ Clinical Dementia Rating score.

cept the striatum. When group averages were compared for AD (see Table 2; Figs 4 and 5), the severity and distribution of cerebral hypometabolism was similar in early- and late-onset $\mathrm{AD}$ subjects, ie, a typical $\mathrm{AD}$ pattern of hypometabolism in association cortex, especially parietal, with metabolic sparing of striatum, thalamus, pre- and postcentral gyrus, primary visual cortex, and hippocampus (medial temporal) cortex [19]. However, the pattern of $\left[{ }^{123} \mathrm{I}\right] \mathrm{IBVM}$ binding differed between groups. In early-onset $\mathrm{AD}$, binding was extensively decreased by about $30 \%$ throughout the cerebral cortex and was especially decreased in temporal cortex (42\%). In late-onset $\mathrm{AD}$, only temporal cortex binding was significantly reduced (28\%); hippocampal binding was reduced about $30 \%$ in both $\mathrm{AD}$ groups.

\section{Parkinson's Disease}

ANOVA indicated significant differences between groups (control, PD without dementia, PD with dementia) in all regions except the striatum and the thalamus. In group averages for PD without dementia (see Table 3; Fig 6), metabolism was mildly (10\%) reduced in occipital, primary visual, and posterior cingulate cortex and hippocampus. $\left[{ }^{123} \mathrm{I}\right] \mathrm{IBVM}$ binding was reduced moderately $(20 \%)$ in the parietal and occipital cortex, but not significantly in the hippocampus. In contrast, PD subjects with dementia had more extensive meta- 


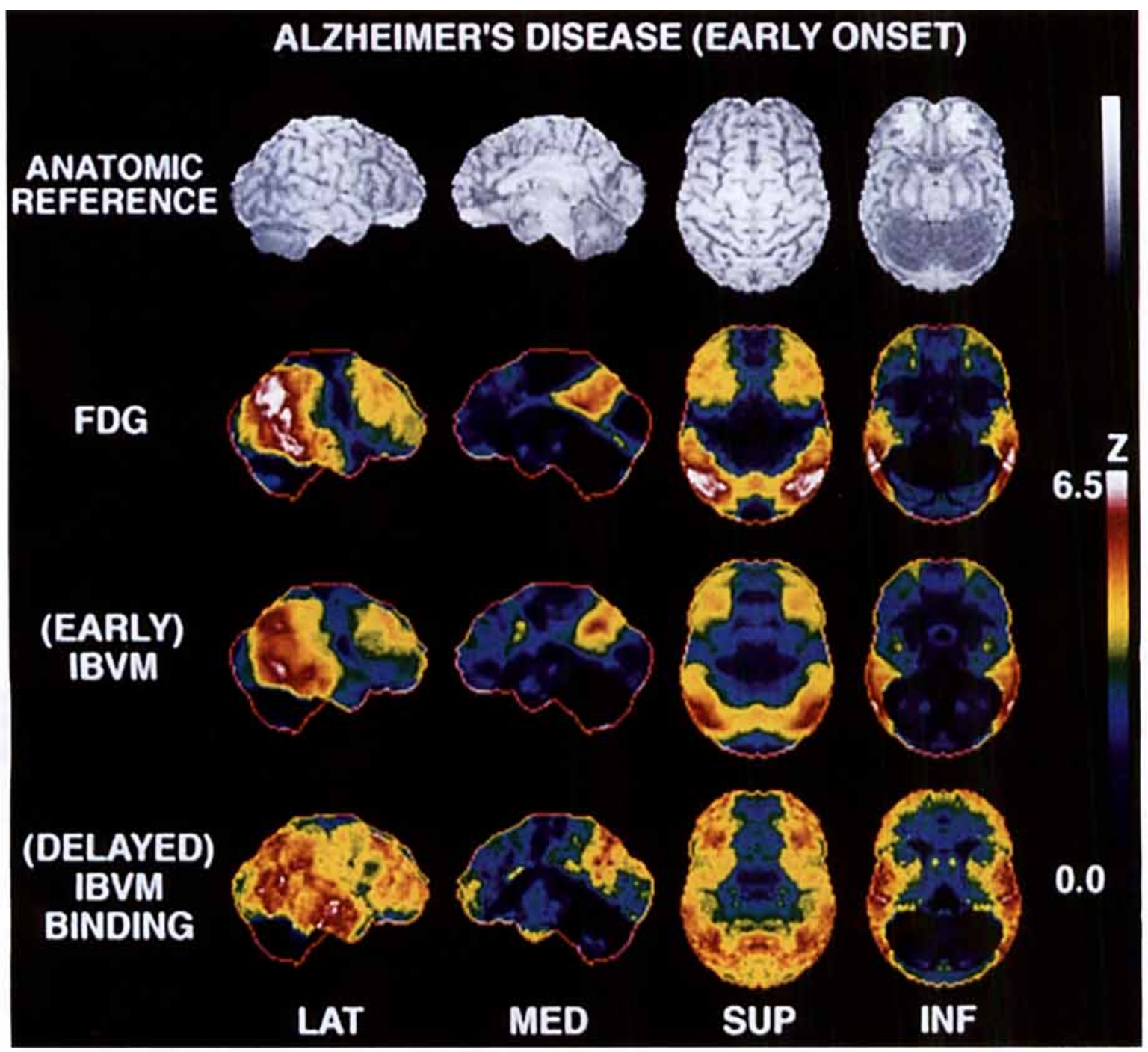

Fig 4.

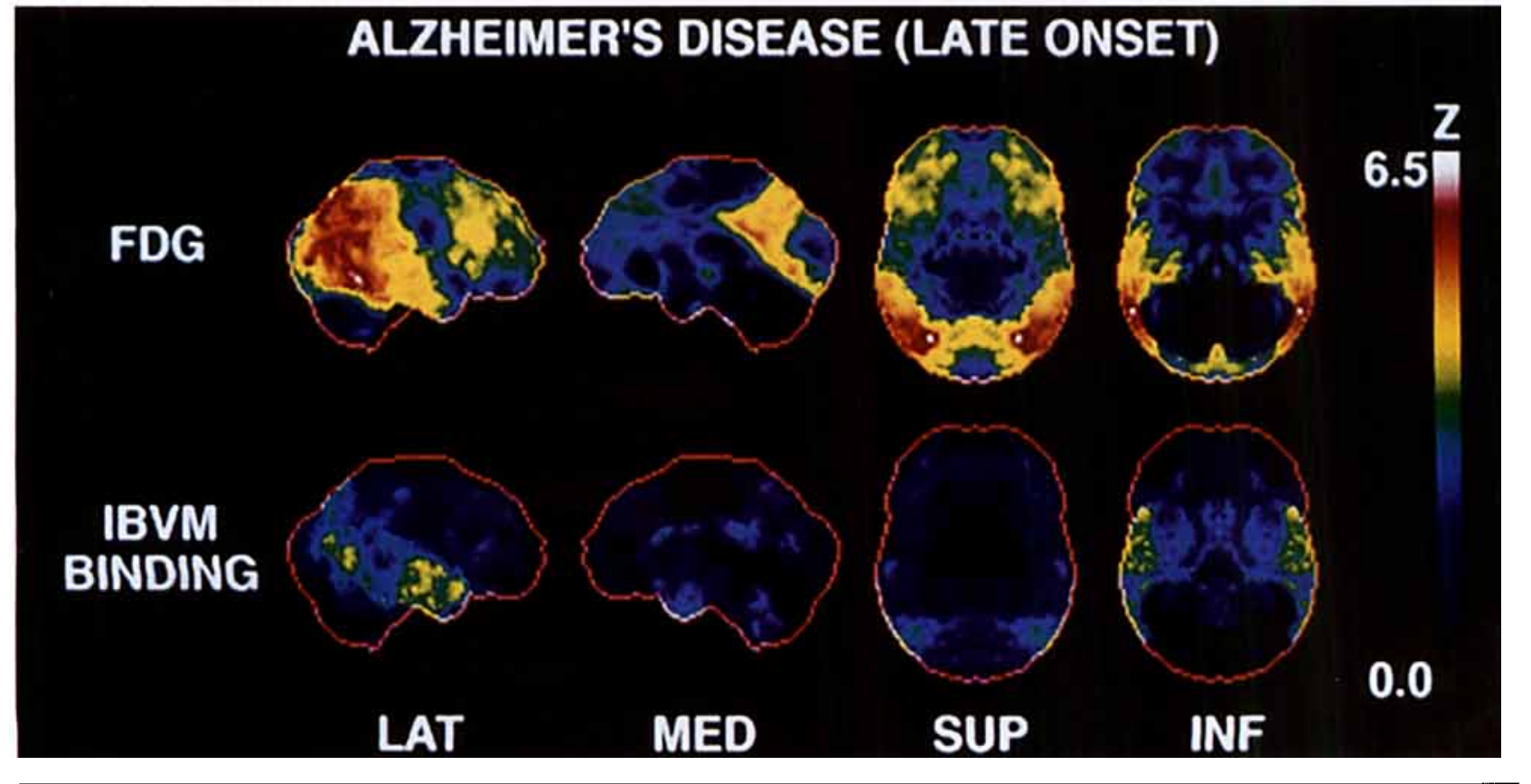

Fig 5. 
bolic (12-23\%) and $\left.{ }^{123} \mathrm{I}\right] \mathrm{IBVM}$ binding reductions $(33-45 \%)$, similar to the severity and neocortical distribution of deficits we had found in early-onset AD.

\section{Influence of Atrophy}

Cortical atrophy was similar in early- and late-onset $\mathrm{AD}$, somewhat less severe in PD with dementia, and did not differ from normal controls in PD without dementia. For example, the corresponding values for [ $\left.{ }^{123} \mathrm{I}\right] \mathrm{IBVM}$ tissue fraction in temporal cortex (percentage of mean normal) were $86 \pm 10,87 \pm 7,90 \pm 9$, and $99 \pm 7$, respectively. In most cortical regions, atrophy accounted for a very small part of measured binding and metabolic reductions (Table 4). After corrections for atrophy, $\left[{ }^{123} \mathrm{I}\right] \mathrm{IBVM}$ binding in early-onset $\mathrm{AD}$ subjects was still decreased by about 20 to $35 \%$ in hippocampus and frontal, temporal, parietal, occipital, primary visual, and posterior cingulate cortex; the concomitant corrected decreases in glucose metabolic rate were about 10 to $25 \%$ in frontal, temporal, parietal, occipital, and posterior cingulate cortex. Atrophy-corrected $\left[{ }^{123} \mathrm{I}\right] \mathrm{IBVM}$ binding in demented PD subjects was still decreased by about 30 to $40 \%$ in frontal, temporal, parietal, occipital, primary visual, and posterior cingulate cortex; corrected glucose metabolism was reduced by about 10 to $20 \%$ in parietal, occipital, primary visual, and posterior cingulate cortex.

\section{Discussion}

Validity of the [123 I]Iodobenzovesamicol Method

After initial demonstrations that vesamicol binding to VAChT parallels the normal brain distribution of other presynaptic cholinergic markers such as ChAT [28, 29], lesion experiments [30] and postmortem studies of $\mathrm{AD}$ cortex [30-32] demonstrated divergence between ChAT activity (marked decreases) and vesamicol binding (no decreases). These discrepancies have since been explained largely as due to the presence of an interfering site in the vesamicol binding assay, the vesamicol binding protein (VBP), which is not found specifically in neurons and which is not related to the vesamicol receptor (VR) [33]. Benzovesamicol and 5-substituted benzovesamicols not only have less affinity for VBP than vesamicol itself [33], but their affinity for VR, based on revised estimates in a more recent report [34], is more than 100-fold greater. The affinities of many of the benzovesamicols for the VR approach the picomolar range, whereas their affinity for VBP is greater than micromolar. This led to our choice of $\left[{ }^{123} \mathrm{I}\right] \mathrm{IBVM}$ $[1,16,35]$ for tomographic brain imaging studies aimed at in vivo mapping of presynaptic VAChT. More recently, the cerebral distribution of VAChT has been shown to be identical to ChAT, further supporting its use as a marker for cholinergic neurons [36]. The human VAChT cDNA encoding it has been cloned and used to localize the VAChT gene, which occupies the same chromosome position as the ChAT gene [36].

The in vivo $\left[{ }^{123} \mathrm{I}\right] \mathrm{IBVM}$ method is now validated further by our finding cholinergic deficits in the same neocortical distributions as have been reported consistently for postmortem $\mathrm{AD}$ and PD brain. These binding declines are not regional artifacts caused only by neocortical atrophy or by reductions in tracer delivery. Our estimates from coregistered MRI scans indicate that atrophy can influence the scan measures of diseaserelated binding or metabolic declines reported here, but not primarily (see Table 4). This is confirmed further by a lack of concordance found between local binding reductions and coexisting atrophy. For example, when early-onset $\mathrm{AD}$ patients were compared with late-onset patients, neocortical atrophy was similar, but cerebral cortical $\left[{ }^{123} \mathrm{I}\right] \mathrm{IBVM}$ binding was markedly dissimilar. Furthermore, in demented parkinsonian patients compared with late-onset $\mathrm{AD}$ patients, neocortex had greater $\left[{ }^{123} \mathrm{I}\right] \mathrm{IBVM}$ binding decline in spite of being less atrophic. The extraction of $\left[{ }^{123} \mathrm{I}\right] \mathrm{IBVM}$ is low $(8 \%)$ and decreases in local binding measures are not in a one-to-one relationship with decreases in local delivery, or perfusion. To the contrary, we found greater decreases in $\left.{ }^{[23} \mathrm{I}\right] \mathrm{IBVM}$ binding than in corresponding $\left[{ }^{123} \mathrm{I}\right] \mathrm{IBVM}$ transport and a lack of regional

Fig 4. Early-onset Alzheimer's disease $(A D)(n=13)$; summations of [223 IJiodobenzovesamicol ([23I]IBVM) single-photon emission computed tomographic and $\left.{ }^{18} F\right]$ fluorodeoxyglucose (FDG)-positron emission tomographic (PET) scan data shown as $\mathrm{Z}$ scores plotted as three-dimensional stereotactic surface projections. Early IBVM images (at 0-30 minutes) reflected perfusion and thus resembled closely the corresponding FDG metabolic images. Note nearly identical sparing of pre-and postcentral gyrus, primary visual cortex, and hippocampus (medial temporal lobe cortex). Delayed IBVM images (at 22 bours) reflected binding to vesicular acetylcholine transporter and appeared quite different. In early-onset $A D, I B V M$ binding was reduced in the entire cerebral cortex and in the hippocampus (medial temporal cortex). $L A T=$ lateral; $M E D=$ medial; $S U P=$ superior; $I N F=$ inferior.

Fig 5. Late-onset Alzheimer's disease $(A D)(n=9)$; summations of $\left.\Gamma^{123} I\right]$ iodobenzovesamicol ([123IIBVM) single-photon emission computed tomographic and $\left[{ }^{18}\right.$ F]fuorodeoxyglucose $(F D G)$-positron emission tomographic (PET) scan data shown as $\mathrm{Z}$ scores plotted as three-dimensional stereotactic surface projections. Although the distribution of FDG deficits (metabolic) in late-onset AD closely resembled those in early-onset AD (see Fig 4), IBVM binding deficits did not. Binding deficits involved only the lateral temporal cortex and hippocampus. $L A T=$ lateral; $M E D=$ medial; $S U P=$ superior; $I N F=$ inferior. 


\section{PARKINSON'S DISEASE}

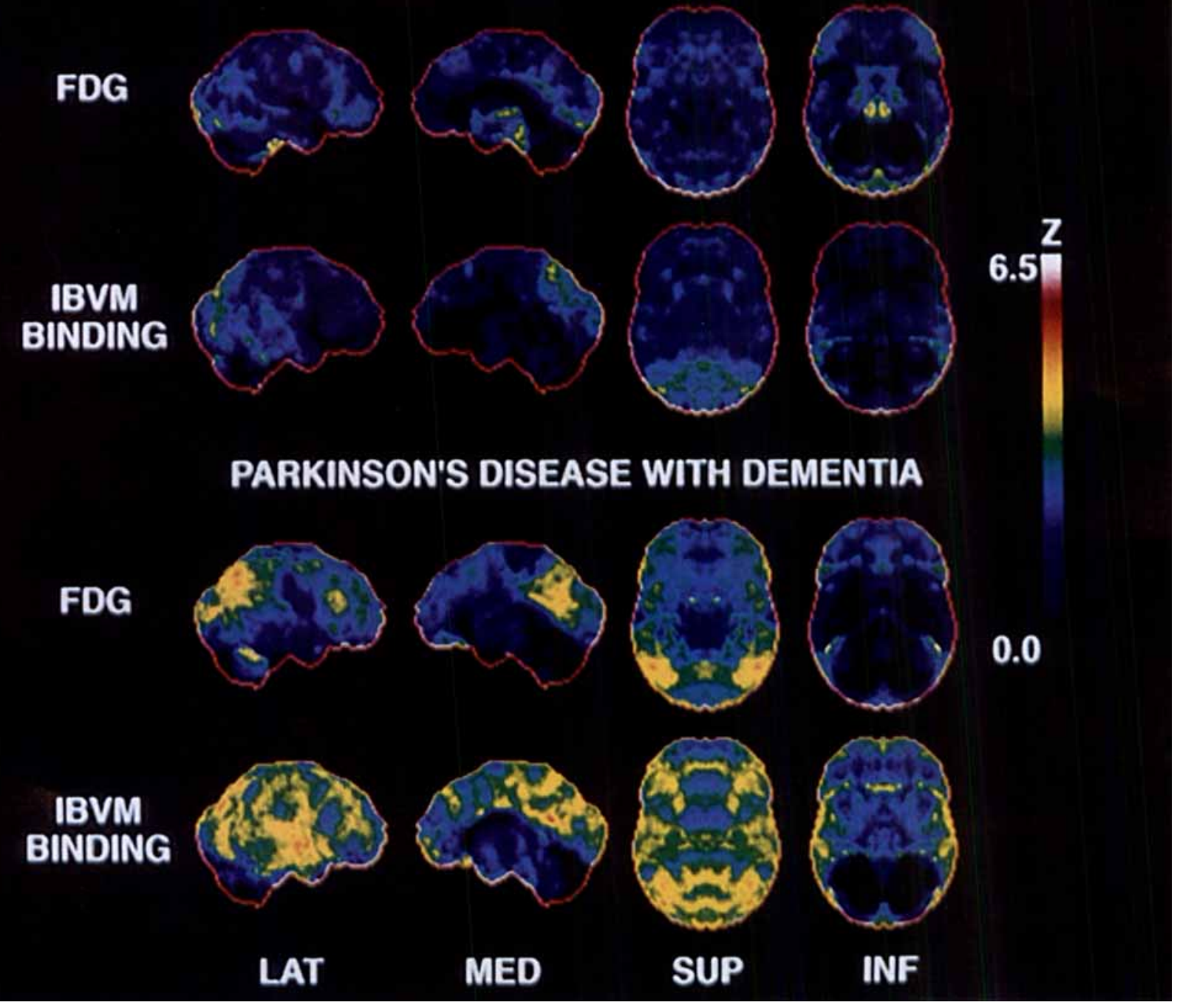

Fig 6. Parkinson's disease (PD); summations of [123 I]iodobenzovesamicol (I23I]IBVM) single-photon emission computed tomo-

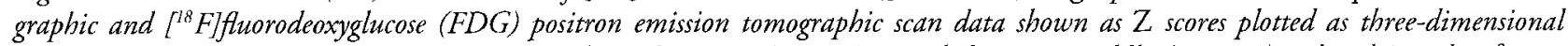
stereotactic surface projections. (Top) In PD without dementia $(n=9)$, metabolism was mildly $(7-12 \%)$ reduced in orbitofrontal, occipital, primary visual, and posterior cingulate cortex and hippocampus. IBVM binding was reduced moderately (20\%) in the parietal and occipital cortex but not significantly in the hippocampus. (Bottom) In contrast, PD subjects with dementia ( $n=$ 6) had more severe and more extensive cortical hypometabolism and cortical IBVM binding decreases (34\%), which were similar in severity and distribution to those seen in early-onset $A D$ (see Fig 4). LAT =lateral; $M E D=$ medial; SUP $=$ superior; INF $=$ inferior.

concordance between perfusion-related and bindingrelated images. Since perfusion and metabolic deficits are equivalently coupled in AD [37], FDG (metabolic), early [ $\left.{ }^{123} \mathrm{I}\right] \mathrm{IBVM}$ (perfusion), and parametric $\left.{ }^{[123} \mathrm{I}\right]$ IBVM $K_{1}$ (transport) images were predictably similar to each other, but were quite different from delayed $\left[{ }^{123} \mathrm{I}\right] \mathrm{IBVM}$ and parametric $\left[{ }^{123} \mathrm{I}\right] \mathrm{IBVM} k_{3}$ images of binding (see Fig 4).

\section{Normal Aging}

We found only small age-dependent losses of cholinergic terminals in normal aging, a finding compatible with most postmortem studies of cholinergic changes with aging [15]. Cholinergic hypotheses of age-related memory dysfunction [38] have arisen largely from studies of pharmacologically induced cholinergic deficits and enhancements in aged laboratory animals. 


\begin{tabular}{|c|c|c|c|c|c|c|c|c|c|c|c|c|}
\hline & \multicolumn{6}{|c|}{$\left[{ }^{123} \mathrm{I}\right] \mathrm{IBVM}$ Binding Reductions } & \multicolumn{6}{|c|}{ Metabolic Reductions } \\
\hline & \multicolumn{3}{|c|}{$\begin{array}{l}\text { Early-Onset AD } \\
\qquad(\mathrm{n}=9)\end{array}$} & \multicolumn{3}{|c|}{$\begin{array}{l}\text { Demented PD } \\
\quad(\mathrm{n}=6)\end{array}$} & \multicolumn{3}{|c|}{$\begin{array}{l}\text { Early-Onset AD } \\
\qquad(\mathrm{n}=9)\end{array}$} & \multicolumn{3}{|c|}{$\begin{array}{l}\text { Demented PD } \\
\quad(\mathrm{n}=6)\end{array}$} \\
\hline & $\mathrm{T}$ & A & $\mathrm{A} / \mathrm{T}$ & $\mathrm{T}$ & A & $\mathrm{A} / \mathrm{T}$ & $\mathrm{T}$ & A & $\mathrm{A} / \mathrm{T}$ & $\mathrm{T}$ & A & $\mathrm{A} / \mathrm{T}$ \\
\hline \multicolumn{13}{|l|}{ Cerebral cortex } \\
\hline Frontal & 32 & 13 & 0.41 & 30 & 5 & 0.17 & 20 & 16 & 0.80 & 14 & 7 & 0.50 \\
\hline Temporal & 41 & 9 & 0.22 & 34 & 7 & 0.21 & 21 & 11 & 0.52 & & & \\
\hline Parietal & 42 & 5 & 0.12 & 37 & 1 & 0.03 & 32 & 7 & 0.22 & 20 & 2 & 0.10 \\
\hline Occipital & 35 & 6 & 0.17 & 36 & 1 & 0.03 & 17 & 8 & 0.47 & 15 & 3 & 0.20 \\
\hline Primary visual & 22 & 1 & 0.05 & 30 & 1 & 0.03 & & & & 14 & 1 & 0.07 \\
\hline Postcingulate & 29 & 9 & 0.31 & 41 & 3 & 0.07 & 27 & 8 & 0.30 & 24 & 4 & 0.17 \\
\hline Antecingulate & 14 & 9 & 0.64 & & & & & & & & & \\
\hline Hippocampus & 37 & 0 & 0.00 & & & & & & & & & \\
\hline
\end{tabular}

${ }^{3}$ Total reductions $(T)$ and reductions due to atrophy alone $(A)$ are mean percentages of normal values $(n=10)$ from data sets made with and without atrophy correction. A/T is the fraction of overall measured reduction which is due to atrophy alone. Listed regions differ significantly from normal as listed in Tables 2 and 3.

Postmortem studies of human brain fail to demonstrate consistently that cholinergic decline is a consequence of normal human aging [15]. Still, one more recent report [39] describes marked ChAT decline in the normally aging hippocampus after the age of 40 years. Our $\left[{ }^{123}\right.$ I]IBVM scans demonstrate no such age-dependent decline in hippocampal cholinergic terminals and only a small $(3.7 \%)$ decline per decade in neocortical cholinergic terminals.

\section{Alzheimer's Disease}

In $\mathrm{AD}$, our in vivo measures of cholinergic terminal deficit generally matched in distribution those reported for postmortem measures of ChAT activity decline but were less severe. Postmortem ChAT activity is found reduced most severely in temporal cortex [40], is less severely reduced in other neocortex and hippocampus [4-6], but is not reduced in striatum $[4,40,41]$, a pattern that gave rise to the cholinergic hypothesis that attributes this deficit to selective loss of cholinergic neurons in the basal forebrain, the source of afferent projections to neocortex and hippocampus [9, 11, 42]. Our binding patterns were similar in more advanced $\mathrm{AD}$ patients, but in mildly demented patients, binding measures differed according to age of onset.

In mildly demented $A D$ patients, we found widespread loss of cholinergic terminals in neocortex and hippocampus in early-onset disease, but in late-onset disease significant reductions were limited to temporal cortex and hippocampus. When dementia was severe, we found terminal deficits were equally severe and extensive in all AD patients (see Fig 3). This should be expected. Neuropathological abnormalities of younger $\mathrm{AD}$ patients are more severe than those of older $\mathrm{AD}$ patients [43]. There is postmortem evidence that cholinergic deficits differ in early- and late-onset AD. In early-onset $\mathrm{AD}$, severe, widespread ChAT reductions have been found in neocortex and hippocampus [44, 45], but in late-onset $\mathrm{AD}$ the ChAT reductions have been reported to be limited to temporal cortex [45] or to hippocampus [44]. Nucleus basalis degeneration might account for this difference; neuronal loss in the nucleus basalis is extensive in early-onset $\operatorname{AD}[46,47]$, whereas this neuronal population may be near normal in late-onset $\mathrm{AD}[47,48]$. Accordingly, the $\left[{ }^{123} \mathrm{I}\right] \mathrm{IBVM}$ scans would be demonstrating primarily an innominatocortical cholinergic system degeneration as the early process in early-onset $\mathrm{AD}$, and a septohippocampal cholinergic system degeneration as the early process in late-onset AD. More simply, less cholinergic deficit may be needed in older patients to elicit mild symptoms.

Our local measures of metabolic decline and of cholinergic terminal decline were discordant in $\mathrm{AD}$. This is expected because the cortical pattern of metabolic change in $\mathrm{AD}$ cannot be explained by a more diffuse loss of cholinergic afferents. In the resting state, the FDG-PET determination of local glucose utilization is associated closely with local overall synapse density [49]. Because cholinergic terminals represent only 6 to $7 \%$ of total terminals in neocortex [50], a local loss of cholinergic neurons/synapses alone has little effect on local overall neuron/synapse numbers, and therefore litthe effect directly on local glucose utilization. Each of our $\mathrm{AD}$ patients, in both early- and late-onset groups, was selected to have an FDG-PET pattern that has been reported extensively to be typical of AD [19], ie, hypometabolism in cerebral association cortex but almost normal metabolism in sensorimotor cortex, primary visual cortex, hippocampus, striatum, thalamus, pons, and cerebellum. This pattern of metabolic decline matches closely the postmortem $\mathrm{AD}$ distribution 
of overall neuronal degeneration [51] and synapse loss [52]. In $\mathrm{AD}$ striatum, we found cholinergic terminal density was normal, like metabolism. Yet, in cerebral cortex of mildly demented patients, the extent and severity of terminal density loss depended on age of onset but hypometabolism did not. The primary visual cortex in $\mathrm{AD}$ has no decline in either overall neuron density [53], or overall synaptophysin-marked synapse density [54], but undergoes a marked loss of ChAT activity [54]; correspondingly, in early-onset $\mathrm{AD}$ we found normal metabolism but decreased cholinergic terminal density. In $\mathrm{AD}$ hippocampus (ie, medial temporal cortex), we found decreased cholinergic terminal density, which agrees with classic postmortem evidence of marked ChAT activity decline, but we found no reduction in $\mathrm{AD}$ hippocampal metabolism. Our metabolic findings agree with other reports that PET measures of glucose metabolism are normal in AD hippocampus [55-57], even though computed tomographic measures of the thickness of the medial temporal lobe indicate progressive atrophy in $\mathrm{AD}[58,59]$. This discrepancy may be explained by the overall rarity of cholinergic synapses in medial temporal cortex. Also, overall synapse density has been reported to be preserved in $\mathrm{AD}$ hippocampus in spite of coexisting neuron loss $[52,60]$, a process that would tend to preserve metabolism within a shrunken structure.

\section{Parkinson's Disease}

In $\mathrm{PD}$, our in vivo imaging demonstrated that younger nondemented patients had mild hypometabolism, which was generalized in neocortex, and had mild cholinergic terminal reductions $(20 \%)$, which were restricted to parietal and occipital cortex (see Table 2). We found no evidence of cholinergic deficit in a preferentially frontal location, which has been implicated as a cause of frontal lobe dysfunction in early PD $[8,61]$. In older PD patients who were demented, neocortical (especially parietal) cortex was more severely hypometabolic, consistent with previous reports $[26,62]$. Cholinergic terminal reductions were more severe and extended now throughout the entire neocortex, but reductions were inconsistent within the hippocampus (see Table 2). These in vivo measures of cholinergic terminal decline were less severe, but similarly located, compared with postmortem measures reported for ChAT in PD. In PD, with or without dementia, striatal ChAT activity is normal $[7,63]$. However, in nondemented PD patients, ChAT activity is reduced in neocortex and hippocampus $[7,8,63]$ and cells are lost within the nucleus basalis [64]. In demented PD patients, ChAT activity is further reduced [7, 8, 63], more so in neocortex than in hippocampus [65]. Our scan findings agree with this postmortem evidence, which has suggested that a primarily innominatocorti$\mathrm{cal}$ cholinergic system degeneration appears early in PD and then worsens in older PD patients with the appearance of dementia. For similar age groups, our scan findings in parkinsonian dementia (age, $77 \pm 5$ years) form a contrast with those we found in late-onset $\mathrm{AD}$ (age, $76 \pm 5$ years), where cholinergic terminal loss was focused primarily to hippocampus rather than to neocortex (see Table 2). These results are in harmony with postmortem evidence that has suggested a primarily septohippocampal cholinergic system degeneration in $\mathrm{AD}[44,45]$.

\section{Terminal Loss, Enzyme Loss, and Cholinergic System Function}

Reductions were consistently less severe for scandetermined cholinergic terminal densities than those reported in $\mathrm{AD}$ and $\mathrm{PD}$ for postmortem-determined ChAT activities. This discrepancy cannot be explained away solely as an artifact of emission tomography consequent on partial volume effects [66]. Instead, our data are more likely consistent with a cholinergic degenerative process in which enzymatic activity fails prior to actual loss of terminals. Our scan measures of cholinetgic terminal integrity suggest that the cholinergic neuronal system is not so devastated in $\mathrm{AD}$ or $\mathrm{PD}$ as implied by postmortem determinations of ChAT activity, and can be largely intact throughout the cerebral cortex in late-onset $\mathrm{AD}$ patients when they are only mildly demented. These findings conform to a concept, usually applied to the basal forebrain cholinergic neurons $[2,3,47]$, that enzymatic dysfunction precedes actual neuronal loss in AD. Viewed in perspective, terminal loss is only one component in a complex mix of ongoing degenerative and compensatory processes that affect the failing cholinergic system. Measures of cholinergic terminal density, or of ChAT activity for that matter, are only resting or static properties of the cholinergic system, as opposed to more functional or dynamic properties, such as rates of ACh synthesis or neuronal responsivities to $\mathrm{ACh}$ [15]. Eventually, such dynamic measures might provide more direct and satisfying descriptions of cholinergic impairment, but they cannot be determined now in living patients.

\section{Conclusions}

We conclude from our scan data that cortical cholinergic terminals undergo only small age-dependent loss in normal aging, are depleted more in mildly demented $\mathrm{AD}$ patients when disease onset is earlier than age 65 years rather than later, and are not so devastated in $\mathrm{AD}$ or $\mathrm{PD}$ as implied by postmortem determinations of ChAT activity. These results are additional evidence that cholinergic neurons in normal aging, $\mathrm{AD}$, and $\mathrm{PD}$ are not lost to the same extent as are dopaminergic neurons in normal aging and PD, and that the survival of these neurons can be monitored with noninvasive imaging. Further in vivo studies with $\left.{ }^{[23} \mathrm{I}\right] \mathrm{IBVM}-$ 
SPECT should help determine the temporal and spatial sequence of declines in cerebral cholinergic terminal integrity from the earliest stages of $\mathrm{AD}$ and $\mathrm{PD}$.

Supported in part by US Public Health Service grants RO1 NS 24896, P50 AG08671, MO1-RR00042, and RO1 NS25656 and Department of Energy grant DE-FG02-87ER60561.

We thank Michael R. Kilbourn, PhD, for helpful neurochemistry advice, James A. Brunberg, MD, for MRI supervision, the chemistry staff for preparing IBVM and FDG, the technologist staff for data acquisition, Leslie Botti, BS, for data workup and analysis, Nancy Lowenbergh, BSN, and the nurses and staff of the Clinical Core of the Michigan Alzheimer's Disease Research Center for subject recruitment, Olga Mancik and Karen Kreutzer for typing the manuscript and the Phoenix Memorial Laboratory of the University of Michigan for use of their radiochemistry facilities.

\section{References}

1. Kuhl DE, Koeppe RA, Fessler JA, et al. In vivo mapping of cholinergic neurons in the human brain using SPECT and IBVM. J Nucl Med 1994;35:405-410

2. Perry RH, Candy JM, Perry EK, et al. Extensive loss of choline aceryltransferase acrivity is not reflected by neuronal loss in the nucleus of Meynert in Alzheimer's disease. Neurosci Lett 1982; 33:311-315

3. Pearson RCA, Sofroniew MV, Cuello AC, et al. Persistence of cholinergic neurons in the basal nucleus in a brain with senile dementia of the Alzheimer's type demonstrated by immunohistochemical staining for choline acetyltransferase. Brain Res 1983;289:375-379

4. Bowen DM, Smith CB, White P, Davison AN. Neurotransmitter-related enzymes and indices of hypoxia in senile dementia and other abiotrophies. Brain 1976;99:459-496

5. Davies P, Maloney AJF. Selective loss of central cholinergic neurons in Alzheimer's disease. Lancet 1976;2:1403

6. Perry EK, Perry RH, Blessed G, Tomlinson BE. Necropsy evidence of central cholinergic deficits in senile dementia. Lancet 1977;1:189

7. Ruberg M, Ploska A, Javoy-Agid F, Agid Y. Muscarinic binding and choline acetyltransferase activity in parkinsonian subjects with reference to dementia. Brain Res 1982;232:129139

8. Dubois B, Ruberg M, Javoy-Agid F, et al. A subcortico-cortical cholinergic system is affected in Parkinson's disease. Brain Res $1983 ; 288: 213-218$

9. Coyle JT, Price DL, DeLong MR. Alzheimer's disease: a disorder of cortical cholinergic innervation. Science 1983;219: $1184-1190$

10. Candy JM, Perry RH, Perry EK, et al. Pathological changes in the nucleus of Meynert in Alzheimer's and Parkinson's diseases. J Neurol Sci 1983;59:277-289

11. Whitehouse PJ, Price DL, Clark AW, et al. Alzheimer disease: evidence for selective loss of cholinergic neurons in the nucleus basalis. Ann Neurol 1981;10:122 -126

12. Perry EK, Tomlinson BE, Blessed G, et al. Correlation of cholinergic abnormalities with senile plaques and mental test scores in senile dementia. Br Med J 1978;2:1457-1459

13. Bowen DM, Benton JS, Spillane JA, et al. Choline acetyltransferase activity and histopathology of frontal neocortex from biopsies of demented patients. J Neurol Sci 1982;57:191-202

14. Bierer LM, Haroutunian V, Gabriel $S$, et al. Neurochemical correlates of dementia severity in Alzheimer's disease: relative importance of cholinergic deficits. J Neurochem 1995;64:749760
15. Decker MW. The effects of aging on hippocampal and cortical projections of the forebrain cholinergic system. Brain Res Brain Res Rev 1987;12:423-435

16. Van Dort ME, Jung Y-W, Gildersleeve DL, et al. Synthesis of the ${ }^{123} \mathrm{I}$ - and ${ }^{125}$ I-labeled cholinergic nerve marker (-)-5iodobenzovesamicol. Nud Med Biol 1993;20:929-937

17. Rogers GA, Parsons SM, Anderson DC, et al. Synthesis, in vitro acetylcholine-storage-blocking activities, and biological properties of derivatives and analogues of trans-2-(4-phenylpiperidino)cyclohexanol (Vesamicol). J Med Chem 1989;32: $1217-1230$

18. McKhann G, Drachman D, Folstein M, et al. Clinical diagnosis of Alzheimer's disease: report of the NINCDS-ADRDA Work Group under the auspices of Department of Health and Human Services Task Force on Alzheimer's disease. Neurology 1984;34:939-944

19. Rapoport SI. Positron emission tomography in Alzheimer's disease in relation to disease pathogenesis: a critical review. Cerebrovasc Brain Metab Rev 1991;3:297-335

20. Hughes CP, Berg L, Danziger WI, et al. A new clinical scale for the staging of dementia. Br J Psychiatry 1982;140:566-572

21. Toorongian SA, Mulholland GK, Jewett DM, et al. Routine production of 2-deoxy-2-[ $\left.{ }^{18} \mathrm{~F}\right]$ fluoro-D-glucose by direct nucleophilic exchange on a quaternary 4-aminopyridinium resin. Int J Rad Appl Instrum [B] 1990;17:273-279

22. Minoshima S, Koeppe RA, Mintun MA, et al. Automated detection of the intercommissural (AC-PC) line for stereotactic localization of functional brain images. J Nucl Med 1993;34: 322-329

23. Talairach J, Tournoux P. Co-planar stereotaxic atlas of the human brain. New York: Thieme, 1988

24. Minoshima S, Koeppe RA, Frey KA, Kuhl DE. Anatomical standardization: linear scaling and non-linear warping of functional brain images. J Nucl Med 1994;35:1528-1537

25. Minoshima S, Frey KA, Koeppe RA, et al. A diagnostic approach in Alzheimer's disease using three-dimensional stereotactic surface projections of $\left[{ }^{18} \mathrm{~F}\right] \mathrm{FDG}$ PET. J Nucl Med 1995; 36:1238-1248

26. Kuhl DE, Metter EJ, Benson DF, et al. Similarities of cerebral glucose metabolism in Alzheimer's and parkinsonian dementia. J Cereb Blood Flow Metab 1985;5:S169-S170

27. Pietrzyk U, Herholz K, Heiss WD. Three-dimensional alignment of functional and morphological tomograms. I Comput Assist Tomogr 1990;14:51-59

28. Marien MR, Parsons SM, Altar CA. Quantitative autoradiography of brain binding sites for the vesicular acetylcholine transport blocker 2-(4 phenylpiperidino)cyclohexanol (AH5183). Proc Natl Acad Sci USA 1987;84:876-880

29. Altar CA, Marien MR. $\left[{ }^{3} \mathrm{H}\right]$ Vesamicol binding in brain: autoradiographic distribution, pharmacology, and effects of cholinergic lesions. Synapse 1988;2:486-493

30. Ruberg M, Mayo W, Brice A, er al. Choline acetyltransferase activity and $\left[{ }^{3} \mathrm{H}\right]$ vesamicol binding in the temporal cortex in patients with Alzheimer's disease, Parkinson's disease, and rats with basal forebrain lesions. Neuroscience 1990;35:327-333

31. Kish SJ, Distefano LM, Dozic S, et al. [ $\left.{ }^{3} \mathrm{H}\right]$ Vesamicol binding in human brain cholinergic deficjency disorders. Neurosci Lett $1990 ; 117: 347-352$

32. Hermanowicz NS, Frey KA, Penney JB Jr. Quantitative autoradiography of $\left[{ }^{3} \mathrm{H}\right]$ vesamicol binding to synaptic vesicle uptake sites for acetylcholine in Alzheimer's disease. Neurology 1991; 41:118 (Abstract)

33. Hicks BW, Rogers GA, Parsons SM. Purification and characterization of a nonvesicular vesamicol-binding protein from electric organ and demonstration of a related protein in mammalian brain. J Neurochem 1991;57:509-519

34. Rogers GA, Komreich WD, Hand K, Parsons SM. Kinetic 
and equilibrium characterization of yesamicol receptor ligand complexes with picomolar dissociation constants. Mol Pharmacol 1993;44:633-641

35. Jung Y-W, Van Dort M, Gildersleeve DL, Wieland DM. A radiotracer for mapping cholinergic neurons of the brain. J Med Chem 1990;33:2065-2068

36. Erickson JD, Varoqui H, Schafter MKH, et al. Functional identification of a vesicular acetylcholine transporter and its expression from a "cholinergic" gene locus. J Biol Chem 1994; 269:21929-21932

37. Frackowiak RS, Pozzilli C, Legg NJ, et al. Regional cerebral oxygen supply and utilization in dementia. A clinical and physiological study with oxygen-15 and positron tomography. Brain $1981 ; 104: 753-778$

38. Bartus RT, Dean RL, Beer B, Lippa AS. The cholinergic hypothesis of geriatric memory dysfunction. Science 1982;217: $408-417$

39. Perry EK, Johnson M, Kerwin JM, et al. Convergent cholinergic activities in aging and Alzheimer's disease. Neurobiol Aging 1992;13:393-400

40. Reinikainen KJ, Soininen H, Riekkinen PJ. Neurotransmittet changes in Alzheimer's disease-implications to diagnostics and therapy. J Neurosci Res 1990;27:576-586

41. Araujo DM, Lapchak PA, Robitaille Y, et al. Differential alteration of various cholinergic markers in cortical and subcortical regions of human brain in Alzheimer's disease. J Neurochem 1988;50:1914-1923

42. Perry EK. The cholinergic hypothesis--ten years on. Br Med Bull 1986;42:63-69

43. Hansen LA, DeTeresa R, Davies P, Terry RD. Neocortical morphometry, lesion counts, and choline acetyltransferase levels in the age spectrum of Alzheimer's disease. Neurology 1988; $38: 48-54$

44. Bird TD, Stranahan S, Sumi SM, Raskind M. Alzheimer's disease: choline acetyltransferase activity in brain tissue from clinical and pathological subgroups. Ann Neurol 1983;14:284-293

45. Rossor MN, Iversen LI, Reynolds GP, et al. Neurochemical characteristics of early and late onset types of Alzheimer's disease. $\mathrm{B}_{\mathrm{r}}$ Med J 1984;288:961-964

46. Whitehouse PJ, Price DL, Strubble RG, et al. Alzheimer's disease and senile dementia: loss of neurons in the basal forebrain. Science 1982;215:1237-1239

47. Kerwin JM, Morris CM, Perry RH, Perry EK. Hippocampal nerve growth factor receptor immunoreactivity in patients with Alzheimer's and Parkinson's disease. Neurosci Lett 1992;143: $101-104$

48. Perry EK, Curtis M, Dick DJ, et al, Cholinergic correlates of cognitive impairment in Parkinson's disease: comparisons with Alzheimer's discase. J Neurol Neurosurg Psychiatry 1985;48: 413-421

49. Sokoloff $\mathrm{L}$. The relationship between function and energy metabolism: its use in the localization of functional activity in the nervous system. Neurosci Res Program Bull 1981;19:159-210

50. Richardson PJ. Quantitation of cholinergic synaptosomes from guinea pig brain. J Neurochem 1981;37:258-260

51. Brun A, Gustafson L. Distribution of cerebral degeneration of
Alzheimer's disease. A clinico-pathological study. Arch Psychiat Nervenkr 1976;223:15-33

52. Masliah E, Terry RD, Alford M, et al, Cortical and subcortical patcerns of synaptophysinlike immunoreactivity in Alzheimer's disease. Am J Pathol 1991;138:235-246

53. Mountjoy CQ, Roth M, Evans NJR, Evans HM. Cortical neuronal counts in normal elderly controls and demented patients. Neurobiol Aging 1983;4:1-11

54. Beach TG, McGeer EG. Cholinergic fiber loss occurs in the absence of synaptophysin depletion in Alzheimer's disease primary visual cortex. Neurosci Lett 1992;142:253-256

55. Fukuyama $\mathrm{H}$, Harada $\mathrm{K}$, Yamauchi $\mathrm{H}$, et al. Coronal reconstruction images of glucose metabolism in Alzheimer's disease. J Neurol Sci 1991;106:128-134

56. Nyback H, Nyman H, Blomqvist $G$, et al. Brain metabolism in Alzheimer's dementia: studies of "C-deoxyglucose accumulation, CSF monoamine metabolites and neuropsychological test performance in patients and healthy subjects. J Neurol Neurosurg Psychiarry 1991;54:672-678

57. Durara R, Grady C, Haxby J, et al. Positron emission tomography in Alzheimer's disease. Neurology 1986;36:879-887

58. DeLeon MJ, George AE, Stylopoulos LA, et al. Early marker for Alzheimer's disease: the atrophic hippocampus. Lancet $1989 ; 2: 672-673$

59. Jobst KA, Smith AD, Szatmari M, et al. Rapidly progressing atrophy of medial temporal lobe in Alzheimer's disease. Lancet 1994;343:829-830

60. Scheff SW, Sparks DL, Price DA. Quantitative assessment of synoptic density in the entorhinal cortex in Alzheimer's disease. Ann Neurol 1993;34:356-361

61. Dubois B, Pillon B, Thermitte F, Agid Y. Cholinergic deficiency and frontal dysfunction in Parkinson's disease. Ann Neurol 1990;28:117-121

62. Kuhl DE, Metter EJ, Riege WH. Pattern of local cerebral glucose utilization determined in Parkinson's disease by the $\left[{ }^{18}\right.$ F]fluorodeoxyglucose method. Ann Neurol 1984;15:419424

63. Lange KW, Wells FR, Jenner P, Marsden CD. Altered muscarinic and nicotinic receptor densities in cortical and subcortical brain regions in Parkinson's disease. J Neurochem 1993;60: $197-203$

64. Nakano I, Hirano A. Parkinson's disease: neuron loss in the nucleus basalis without concomitant Alzheimer's disease. Ann Neurol 1984;5:415-418

65. Perry EK, Irving D, Kerwin JM, et al. Cholinergic transmitter and neurotrophic activities in Lewy body dementia-similarity to Parkinson's and distinction from Alzheimer's disease. Alzheimer Dis Assoc Disord 1993;7:69-79

66. Mazziotta JC, Phelps ME, Plummer D, Kuhl DE. Quantitation in positron emission computed tomography: 5 physical anatomical effects. J Comput Assist Tomogr 1981;5:734-743

67. Folstein M, Folstein SE, McHugh PR. "Mini mental state." A practical method for grading the cognitive state of patients for the dinician. J Psychiatr Res 1975;12:189-198

68. Hoehn MM, Yahr MD. Parkinsonism: onset, progression, and mortality. Neurology (Minneap) 1966;17:427-442 